\title{
A Meteorological Experiment in the Melting Zone of the Greenland Ice Sheet
}

\begin{abstract}
Preliminary results are described from a glaciometeorological experiment carried out in the margin (melting zone) of the Greentand ice sheet in the summers of 1990 and 1991. This work was initiated within the framework of a Dutch research program on land ice and sea level change. Seven meteostations were operated along a transect running from the tundra well onto the ice sheet. At the ice edge, humidity, temperature, and wind profiles were obtained with a tethered balloon. On the ice sheet, $90 \mathrm{~km}$ from the edge, a boundary-layer research unit, including a sound detecting and ranging system (SODAR) and a radio acoustic sounding system (RASS), was established.

Although focusing on the relation between surface energy balance, glacier mass balance, and ice flow, the experiment has also delivered a unique dataset on the dynamics of the atmospheric boundary layer around the warm tundra-cold ice sheet transition.

Unexpected behavior was found for the surface albedo during the melt season. Lowest values are not found close to the ice edge, which is usual for glaciers, but higher on the ice sheet. Meltwater accumulation due to inefficient surface drainage was found to be the cause for this.

The wind regime is dominated by katabatic flow from the ice sheet. The katabatic layer is typically $100-200 \mathrm{~m}$ thick. Close to the ice edge, the flow exhibits a very regular daily rhythm, with maximum wind speed in the afternoon. Farther on the ice sheet, the regime changes, and wind speed reaches maximum values in late night early morning.
\end{abstract}

\section{Introduction}

The GIMEX (Greenland Ice Margin Experiment) campaigns form part of a long-term research program on land ice and sea level change, carried out at the Institute for Marine and Atmospheric Research, Utrecht University, in collaboration with the Free University of Amsterdam (Faculty of Earth Sciences) and Amsterdam University (Institute of Physical Geography and Soil Science).

Apart from major input by these universities, the project is funded by a number of bodies/institutions: the European Commission, the Netherlands Organ-

\footnotetext{
"Institute for Marine and Atmospheric Research, Utrecht University Utrecht, the Netherlands

+Faculty of Earth Sciences, Free University of Amsterdam, Amsterdam, the Netherlands

C1993 American Meteorological Society
}

isation forScientific Research, and the Netherlands Ministry of Housing, Physical Planning and Environment.

The more specific scientific goals of the meteorological experiments near and on the ice margin in west Greenland, GIMEX-90 and GIMEX-91, were 1) to obtain a better understanding of how glacier mass balance is related to meteorological conditions; 2) to investigate how the large thermal contrast between the ice-free tundra and the ablation zone of the ice sheet affects local circulations and associated heat transport; and 3) to make a detailed study of the atmospheric boundarylayeroveramelting ice/snow surface.

The more general aspect of the experiments is to support modeling studies that simulate glacier mass balance based on the surface energy budget (e.g., Oerlemans 1991). Here, more accurate schemes to calculate turbulent heat fluxes as well as the surface radiation budget are needed.

In the past, only a few micrometeorological studies have been carried out on the ice sheet. The most extensive ones were those made by Ambach and collaborators during the Expedition Glaciologique Internationale au Groentand (EGIG, West Greenland at about $70^{\circ} \mathrm{N}$ latitude) of 1957 and 1966 , focusing on the radiation budget and energy transfers at and within the ice/snow surface (e.g., Ambach 1963, 1974, 1979). Longer datasets on synoptic observations are of course available from a number of meteorological stations, but these are all along the coast and at a few spots high on the ice sheet where melting hardly occurs (Ohmura 1987).

It is not surprising that the melting zones have been avoided by meteorologists. Transportation over the surface is very difficult because of crevasses, meltwater lakes, and streams. Even the use of helicopters requires great care, as landing can be difficult in areas where slush dominates on the surface. Installing automatic stations poses another problem: the melting rates are so high (up to $5 \mathrm{~m}$ of ice in an ablation season) that sensors mounted on masts drilled into the ice do not maintain a constant distance to the ice surface. Especially when fluxes have to be calculated from profiles, this is unacceptable.

in an attempt to improve current knowledge on micrometeorological processes in the melting zone of 


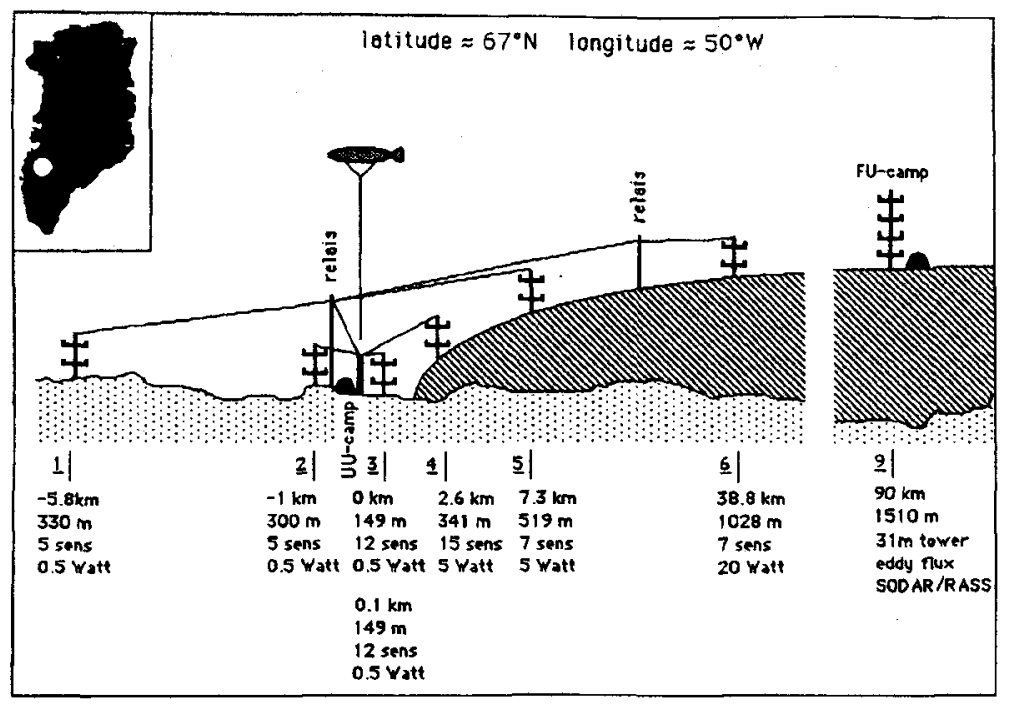

FIG. 1. Setup of the experiment. Meteorological stations were placed along a westeast transect perpendicular to the edge of the Greenland ice sheet, close to Søndre Strømfjord airport $\left(67^{\circ} \mathrm{N}\right)$. Two camps were erected: the UU camp at the ice edge (telemetric data assimilation of sites $1-6$ and balloon profiling) and the FU camp at the boundary-layer station on the ice sheet ( $31-\mathrm{m}$ tower, eddy-flux measurements, SODARRASS profiling). The location is shown in the upper left corner. Listed at each site: distance to reference point, surface elevation, number of sensors, and transmitting power for telemetry.

the Greenland ice sheet, a number of European research institutions have set up a coordinated program. Apart from the universities mentioned above, participating groups come from Switzerland (Eidgenossische Technische Hochschule Zürich), Germany (AlfredWegener-Institut für Polar- und Meeresforschung), and Denmark (the Geological Survey of Greenland, Copenhagen).

For the Dutch component in the program, the area of Søndre Strømfjord was selected (see Fig. 1). It has the advantage of being close to an international airport with relatively easy access to the ice sheet. Also, the meteorological service at the airport appeared to be of great help in providing background information and in serving as a communication center.

A first survey on the ice sheet was made in 1989. Stakes were drilled for mass balance measurements and positioning by GPS (Global Positioning Satellite), which, in the course of time, will give more and more accurate measurements of ice velocity. The meteorological experiments were carried out in the summers of 1990 (GIMEX-90) and 1991 (GIMEX-91).

\section{Setup of experiment}

Figure 1 shows the configuration used during GIMEX-91. Two camps were established, one very close to the ice edge by the University of Utrecht (UU camp) and one on the ice sheet about $90 \mathrm{~km}$ from the edge by the Free University of Amsterdam (FU camp). The number of meteorological stations totaled seven: six masts (numbered 1 to 6 ) telemetering data down to the UU camp, and one boundary-layer station (numbered 9 ) run at the FU camp.

To avoid the problem of increasing distance between sensors and surface, a construction was designed that stands freely on the ice surface. It consists of a regular aluminum mast, with four long legs at the base, making a small angle $\left(10^{\circ}\right)$ with the surface. At the end of these legs, sharp pins are attached to keep the construction in place. A mast of this type was tested in 1989 during a field campaign on the Hintereisferner (a glacier in the Austrian Alps) and appeared to be sufficiently stable. It was then decided to use this design on Greenland as well, at sites 4,5 , and 6 . The masts behaved in a satisfactory way. At the end of the field campaigns, the tilt was small. As the pins/legs melt in the ice, the sensors gradually came somewhat closer to the surface. This is a small effect, however; not more than $0.1 \mathrm{~m}$ in the course of the whole observation period.

Data assimilation of masts 1 to 6 (and one spare at the balloon site), with a total of 64 sensors, was done through a computerized telemetric system, with the steering computers located at the UU camp. Local storage at the masts prevented loss of data when disturbances in the radio connections occurred.

At the UU camp, a cable balloon ( $11 \mathrm{~m}^{3}$, helium) was also operated at a frequency of 4 to 6 times a day, unless wind speed at the surface was higher than 10 $\mathrm{m} \mathrm{s}^{-1}$. At each ascent, profiles of temperature, humidity, wind speed, and direction were taken up to a height of $1200 \mathrm{~m}$. An electronically steered winch was used to control the speed of ascent and descent. In total, about 300 ascents were made.

Power supply for the meteorological stations (for aspirating the thermometers and for the transmitter) was taken care of by solar panels in combination with batteries. Generators were used in the base camp. Two small trucks were available for transportation of material between Søndre Strømfjord and the UU camp.

In addition to the meteorological experiments, mass balance stakes placed in 1989 or 1990 were 
remeasured and positioned. To study the relation between runoff, measured ablation, and measured energy balance at several sites in the ablation zone of the ice sheet, discharge measurements were done in the nearby glacier river.

A more detailed study of the structure of the atmospheric boundary layer was undertaken at the FU camp. This camp, at an elevation of about $1500 \mathrm{~m}$, accommodated four people. Wind speed, temperature, and humidity were measured at 8 levels along a $31-\mathrm{m}$ high tower, wind direction at heights of 2.0 and $31 \mathrm{~m}$.

Turbulence data were obtained in two ways. First, at four levels along the tower, dry- and wet-bulb fluctuations were measured with a sampling rate of 5 $\mathrm{Hz}$. Second, eddy flux measurements with sonic anemometers, thermocouples, and Lyman-Alpha's were carried out at the top of two shorter masts ( 13 and $4 \mathrm{~m}$, respectively), with a $20-\mathrm{Hz}$ sampling rate. The whole system was powered by a 6-kVA diesel generator, while the total energy consumption was about 2.5 kVA. During half an hour every day, the eddy flux measurements were interrupted by dumping the hard disk on tape, so that an almost complete dataset of 28 days was obtained.

For remote probing of the atmospheric boundary layer an acoustic sounder (SODAR) and a RASS system were used, so that wind speed (three components) and temperature profiles up to about $400 \mathrm{~m}$ at 20 levels could be obtained with an averaging period of 1 min. Radiation (global radiation, albedo, and net radiation) and snow temperatures were also determined to have all components of the surface energy budget.

\section{General characteristics of the tundra- ice transition in summer}

It is obvious that the tundra-ice sheet transition forms a tremendous gradient in boundary-layer forcing once the snow cover has disappeared. In the study area, this normally happens in the course of May. On the tundra, the daily mean upward turbulent heat flux on a sunny day is on the order of $350 \mathrm{~W} \mathrm{~m}^{-2}$, whereas in the adjacent melting zone it is directed downwards. This has important dynamic consequences, as will be discussed in a later section. Figure 2 shows the typical pattern of $2-\mathrm{m}$ air temperature. There is a clear coherence among the various sites. The lowest curve in Fig. 2 gives global radiation (daily mean values), showing that the temperature difference between the ice stations (sites 4, 5, 6, 9) and the tundra stations (sites 1 , 2,3 ) tends to be larger on sunny days. The correlation coefficient between global radiation and the temperature difference between sites 1 and 5 is $\mathbf{0 . 5 5}$.

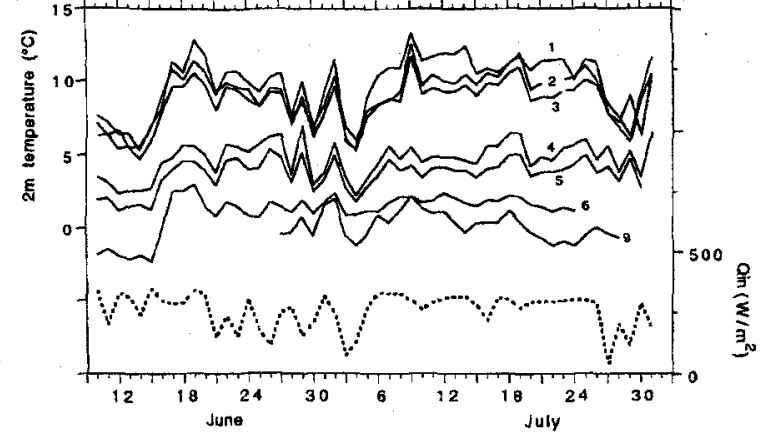

Fig. 2. Daily mean air temperature at $2 \mathrm{~m}$. Sites 1,2 , and 3 are in the tundra; the other sites are on the ice sheet. The dashed curve shows daily mean values of global radiation as measured at site 3 (scale at right).

Synoptic-scale events, such as the arrival of a warm air mass on 16 June, are reflected at all sites. The measurements also reveal that the interdaily variation is larger in the tundra than on the ice sheet, which is not unexpected.

In general, the large-scale flow over the study area was rather weak. Geostrophic winds, as inferred from weather maps prepared by the meteorological service at the airport of Søndre Strømfjord, were in the southeast quadrant most of the time, which is normal for this part of Greenland. On many days, a high pressure area was located over the Greenland ice sheet, with storms moving eastwards over the Atlantic south of Greenland. On a few occasions, a weak depression moved northward along the west coast of Greenland, bringing some precipitation in the study area.

Potential temperature, with reference to sea level, and averaged over the entire measuring period, is plotted in Fig. 3. The data from site 9, covering a shorter period, have been converted to match the observation period for the other sites. The values for the experiment carried out in 1990 are also shown.

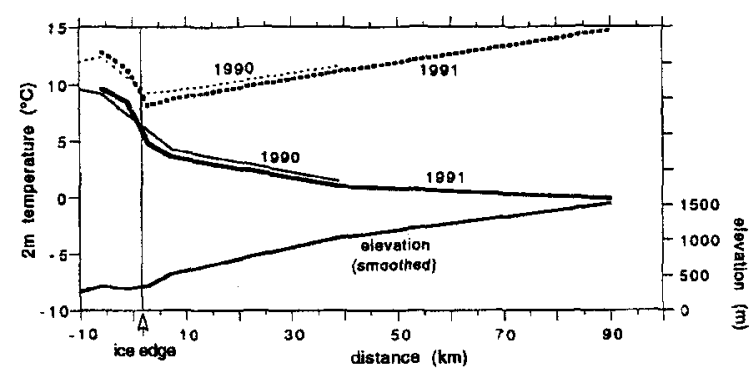

Fig. 3. Mean temperature and potential temperature (dashed) along the transect studied. The 1990 curves represent 31-day mean values, the 1991 curve 53-day mean values. The configuration of stations in the tundra was slightly different in the two years. The lower curve shows the (smoothed) surface elevation for reference. 

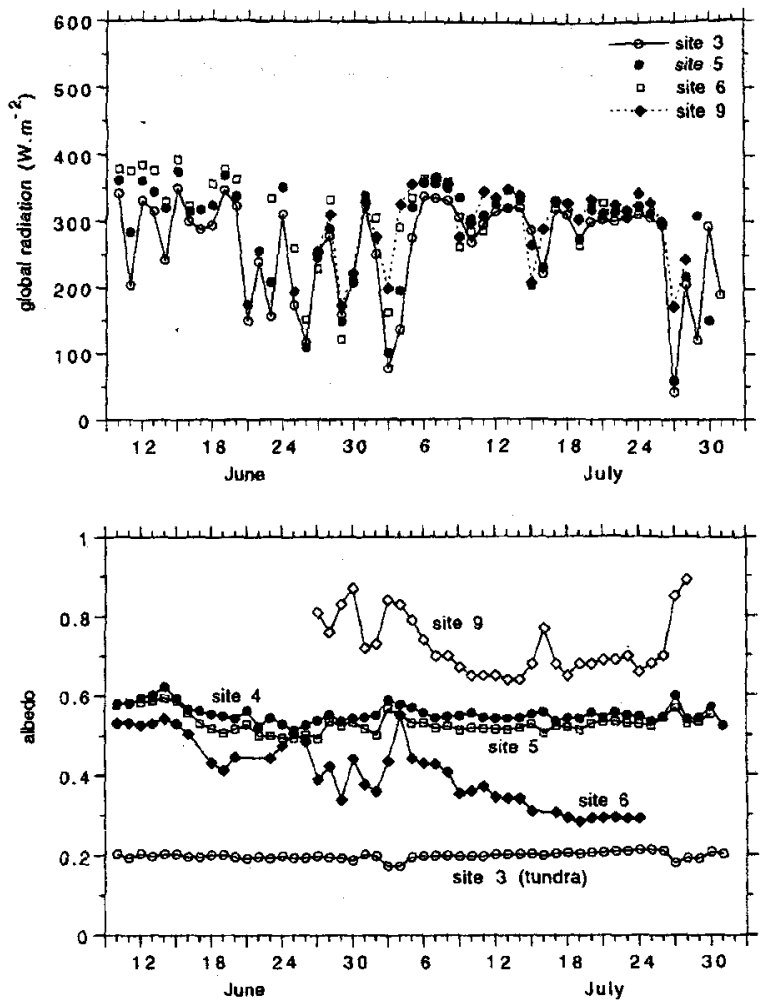

FiG. 4. Upperpanel: Daily mean values of global radiation at sites 3 (tundra), 5, 6, 9 (on the ice sheet). Note the systematic increase of giobal radiation when going on the ice sheet. Lower panel: Daily mean values of the surface albedo at sites $4,5,6,9$ (on the ice sheet), and 3 (tundra). Although higher on the ice sheet, albedo at site 6 is generally lower, especially later in the melting season. This is due to accumulation of meltwater and water-saturated old snow (slush). Periods of bad weather are best reflected at site 9, where fresh snow leads to an immediate increase in albedo (30 June; 3,16 , and 25 July).

The 1990 period was shorter ( 31 days), and centered slightly later in summer, but patterns are remarkably similar. The potential temperature at site 9 on the ice sheet is slightly higher than in the tundra. Near the icesheet edge a significant negative departure occurs. This must be due to the cooling of surface air by a downward turbulent heat flux in the westward-flowing katabatic wind. In the melting zone of the ice sheet, this flow totally dominates the wind regime: more than $95 \%$ of the time, the wind blows from a direction between northeast and south.

Figure 3 shows that the cooling in the downward flow is typically $1 \mathrm{~K}$ over a distance of $10 \mathrm{~km}$. With a typical easterly wind component of $5 \mathrm{~m} \mathrm{~s}^{-1}$, this yields a cooling rate of almost $2 \mathrm{~K} \mathrm{~h}^{-1}$. As the katabatic layer is typically $150 \mathrm{~m}$ thick (this is known from the balloon measurements to be discussed later), a downward turbulent flux of not less than $120 \mathrm{~W} \mathrm{~m}^{-2}$ would be needed to explain this. However, the cooling rate averaged over the depth of the katabatic layer will probably be smaller than that measured at the surface. If it is close to half the surface value, a $60 \mathrm{~W} \mathrm{~m}^{-2}$ turbulent heat flux is required. This is still a fairly large number for a flow with a pronounced stable stratification near the surface. The estimate given here may be somewhat too large, however, as direct radiative cooling of the relatively humid air close to the surface may be significant.

Incoming and outgoing solar radiation was measured at sites $3,4,5,6$, and 9 ; net radiation at sites 4 and 9 only. As shown in the upper panel of Fig. 4 , there appeared to be a consistent increase of global radiation when going on the ice sheet, particularly on clear days. Mean values are listed in Table 1. Although there is a tendency for cloudiness to be smaller on the ice sheet, clear days also contribute considerably to the increase in global radiation. Thus, decreasing atmospheric turbidity and optical air mass must be important factors here. One may speculate that dust stirred up from the dry tundra causes a negative gradient in aerosol concentration when going on the ice sheet.

Daily mean values of the (spectrally integrated) albedo are plotted in the lower panel of Fig. 4. Results are shown for sites 3 (tundra), 4, 5, 6, and 9 (ice sheet). The albedo on the tundra is nearly constant, with excursions to slightly lower values only when the vegetation gets wet on rainy days. The tremendous drop of albedo at site 6 in the course of the melting season is striking. In the beginning of June the value is over 0.5 , and then drops to about 0.28 in the middle of July. Needless to say, this has a large effect on the amount of energy available for melting. The reason for the drop is the abundance of meltwater accumulating at the surface, which is typical for a zone below the equilibrium line (in this region, the equilibrium line is found at a height of about $1500 \mathrm{~m}$ ). One may argue that the low albedo at site 6 need not be representative since it is a point measurement. However, study of an AVHRR image (visible, channel 2) from the NOAA-10 satellite showed a distinct band of low reflectivity, hundreds of kilometers long, running parallel to the ice edge right across site 6 . The sites closer to the ice margin, where surface slopes are larger and drainage of meltwater more efficient, maintain remarkably high albedos throughout the melt season. Snowstorms show up very clearly in the albedo record, of course. The one on 3-4 July is seen as a steep increase in albedo at sites 6 and 9 , but not so much at the "warm" sites 4 and 5 , where the precipitation probably fell as rain. In the tundra the rain causes a drop of the albedo of about 0.02 .

The resulting gradient in mean albedo when going upward on the ice sheet is fairly large. This is in sharp contrast to what is normally found on alpine glaciers, 


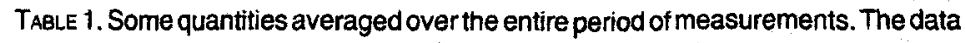
from site 9 have been converted to the observation period for sites 1 to 6 ( 10 June-31 July).

\begin{tabular}{|c|c|c|c|c|c|}
\hline & \multirow{2}{*}{$\begin{array}{c}\text { Tundra } \\
\text { sife } 3\end{array}$} & \multirow[b]{2}{*}{ site 4} & \multicolumn{2}{|c|}{ Ice sheet } & \multirow[b]{2}{*}{ site 9} \\
\hline & & & site 5 & site 6 & \\
\hline Elevation (m MSL) & 149 & 341 & 519 & 1028 & $15+0$ \\
\hline Global radiation $\left(\mathrm{W} \mathrm{m}^{-2}\right)$ & 262 & 303 & 312 & 329 & \\
\hline Albedo & 0.188 & 0.548 & 0.528 & 0.412 & \\
\hline Absorbed solar $\left(\mathrm{W} \mathrm{m}^{-2}\right)$ & 210 & 137 & 147 & 194 & \\
\hline 2-m temperature $\left({ }^{\circ} \mathrm{C}\right)$ & 8.48 & 4.76 & 3.62 & 1.06 & -0.122 \\
\hline Potential temperature $\left({ }^{\circ} \mathrm{C}\right)$ & 11.42 & 8.10 & 8.70 & 11.13 & 14.68 \\
\hline Wind speed $\left(\mathrm{m} \mathrm{s}^{-1}\right)$ & 3.53 & 5.28 & 5.73 & 5.68 & 6.01 \\
\hline
\end{tabular}

Mean 6-m wind speed for sites 3, 4, 5,6 , and 9 is also given in Table 1 . Because of the shorter period of observation, the wind speed at site 9 was adjusted by comparing the record with the same period at the other stations. Wind speeds are generally higher on the ice sheet than in the tundra, but on the ice sheet the differences are small. Figure 6 shows the distribution of wind direction for three sites, based on all hourly values for the 1991 experiment. It is evident that wind on the ice sheet is virtually always from the southeast sector. In the tundra easterly winds also dominate, but are much less pronounced. There is a slight backing of the mean wind when going downward from site 6 toward the ice edge. At this

namely, an increasing albedo when going upward, which finds its origin in the decreasing concentration of dust and morainic material at the surface. Combined with the increasing global radiation, the increase in the amount of absorbed solar radiation thus is a very significant effect. Values are listed in Table I.

As runoff measurements in the nearby glacial river were also carried out, a comparison can be made between measured ice ablation, calculated ablation from the measured energy balance, and meltwater discharge. The analysis is still in progress, and here we show an example of the 1990 record. Figure 5 shows discharge in the local glacial river for a selected period of 12 days. The energy balance of the ice surface at site 4, as calculated from the meteorological data, is also shown. Although the energy balance can be converted to specific ice melt (melt per unit area), an absolute comparison cannot be made because the catchment of the glacial river is unknown. However, a simple estimate shows that the catchment must be rather small, and certainly does not extend to sites 6 and 9 . For this reason, the 1991 gauging station was located at another site (farther downstream in the glacial river system).

Figure 5 shows that the daily cycle in the river discharge is typically one-half to one-third of the base flow. The discharge lags the energy balance by about $8 \mathrm{~h}$. The increasing discharge in the period 25-27 July is associated with high air temperature and the related large turbulent heat flux (even during the night). It takes about one day before the discharge has adjusted to the pronounced drop in the energy balance occurring on 28 July.

For an analysis of the 1991 data, including calculations with a model for glacial discharge, the reader is referred to Van der Wal and Russell (1993). stage it is hard to say whether this is related to the subtle dynamics of the katabatic flow system or a more direct effect of the elevation contours on the ice sheet (an accurate topographic map of the melting zone up to site 9 , or even 6 , is not available).

\section{The local wind regime}

As mentioned earlier, the tundra-ice sheet transition forms a tremendous gradient in boundary-layer forcing once the snow cover on the tundra has disappeared. On the tundra, the upward turbulent heat flux during daytime is so large that a "normal" convective mixed layer develops virtually every summer day. According to the balloon measurements, the depth of this layer is typically $1000 \mathrm{~m}$ in the late afternoon. Altogether, a significant heating of the lower troposphere over the tundra takes place, even on a daily mean basis. Over the ice sheet, cooling dominates. The net radiative balance of the troposphere will be

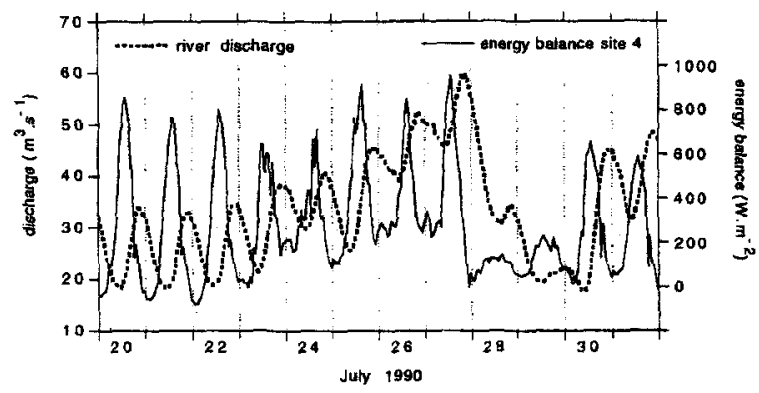

FiG. 5. A comparison of discharge in the glacial river and the surface energy balance calculated from the meteorological observations at site 4 (first station on the ice sheet). 
site 2

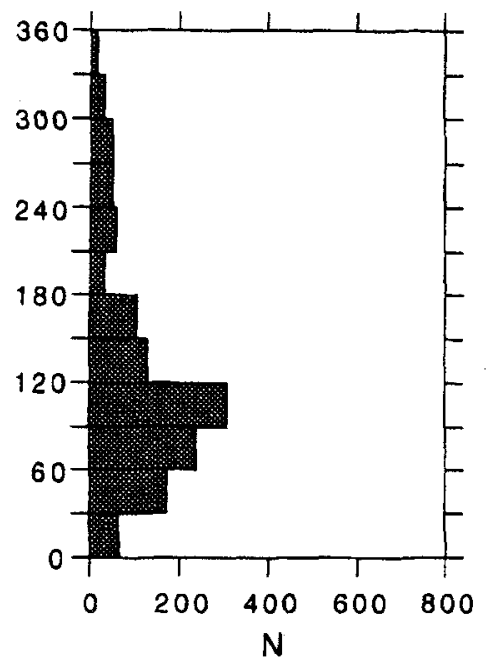

site 4

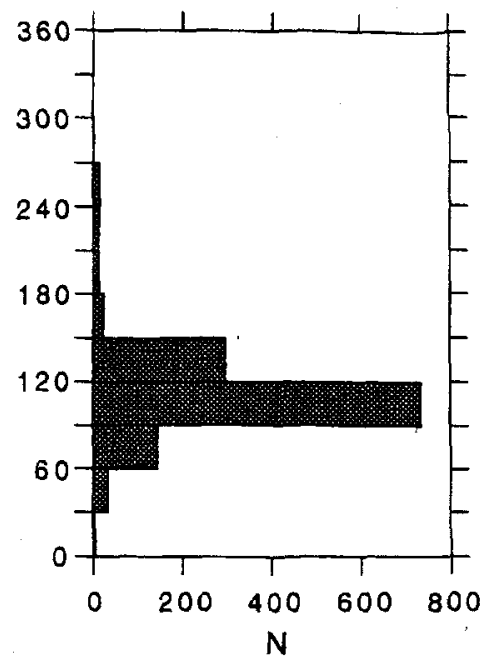

site 6

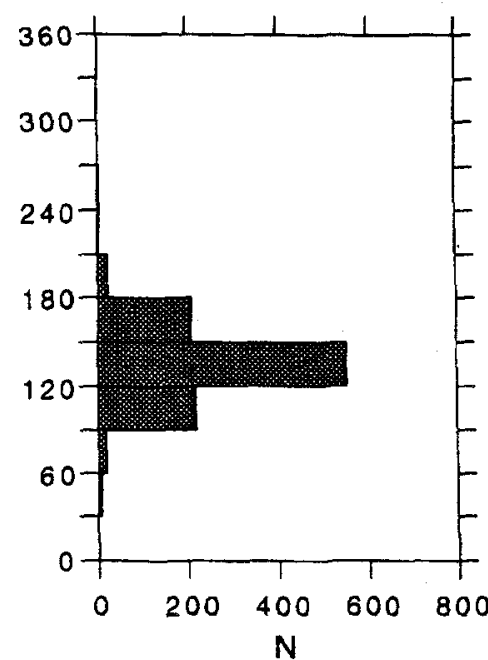

Fig. 6. Histograms of wind direction, based on hourly mean values. Site 2 is in the tundra (about $2 \mathrm{~km}$ from the ice edge); sites 4 and 6 are on the ice sheet.

negative, but, as over the tundra, it is not compensated by an upward turbulent heat flux. Instead, there is a steady downward heat flux toward the melting ice surface. Since the ice-sheet surface has a slope, this must induce katabatic flow.

Figure 7 shows global radiation, temperature, wind speed, and wind direction at site 4 for a 16-day period of fine weather with very little cloud cover. Such periods are a common feature of the summer climate of west Greenland. The response of the boundary layer to the diumal forcing at mast 4 is of a striking regularity. The daily cycle in wind speed is a pronounced and persistent feature. The maximum wind speed occurs in the late afternoon, at or slightly after the time that air temperature reaches its highest value. So the maximum wind speed occurs when the stratification near the ice surface is most stable, suggesting that a driving force proportional to air temperature is at work. The horizontal pressure gradient associated with the thermal contrast between tundra and ice, with its strong daily rhythm, must be the forcing agent. The constancy of the wind direction is notable. The wind always blows from the east-to-southeast sector, except during the wind minimum-in many cases it then backs to northeast for a short while.

As the temperature over the melting ice surface depends to a large extent on downward mixing of warm air, it is not surprising to find temperature maxima shortly after the time of maximum wind speed. The fact that maximum temperature at the tundra sites occurs, on average, one to two hours earlier than at site 4 is consistent with this view.

The picture becomes more complicated when look- ing at the daily cycles in wind speed and temperature at the other sites on the ice sheet. Figure 8 shows daily cycles averaged over the entire measuring period. Here, remarkable differences show up. The pattern for
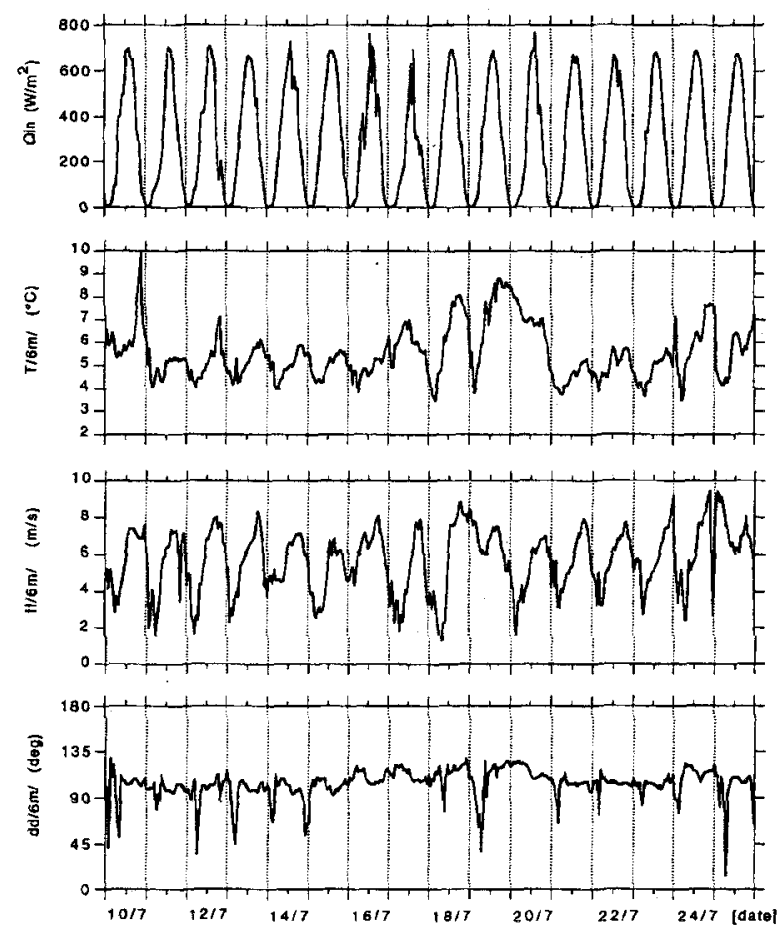

FIG. 7. A record of 16 days of fine weather from site 4 . Shown are global radiation, air temperature, wind speed, and wind direction (all at $6 \mathrm{~m}$ ). 
site 1 (tundra, $7 \mathrm{~km}$ from the ice edge) is typical for a regime in which a convective mixed layer is established every day: a minimum in wind speed in late night due to a stable stratification and a maximum in the afternoon when turbulent exchange is most effective. At site 4 the daily cycle is similar, but has an entirely different cause: the wind is generated locally and varies as a direct response to the forcing as discussed above. Also at site 5 , located $9 \mathrm{~km}$ from the ice edge, the wind reaches a maximum in the late afternoon, but the daily variation is smaller now. Most interesting, the daily cycle is not present at site 6-here the wind speed is even slightly larger during night and early morning. At site 9 , located $90 \mathrm{~km}$ from the ice edge, the nightly wind maximum is a significant feature. This suggests that further on the ice sheet the local radiative flux divergence of the near-surface air now becomes the dominating force.

\section{The katabatic regime dominates the} circulation over the melting zone of the ice sheet. It exhibits a daily cycle, most pronounced at the ice edge, superposed on a background flow of typically $4 \mathrm{~m} \mathrm{~s}^{-1}$.

A further interesting feature shows up when comparing the mean daily temperature cycles. At sites 6 and 9 , the maximum temperature occurs significantly earlier than at sites 4 and 5. It appears to be dominated by the local radiative heating at and close to the surface. At sites 4 and 5 the effect of the radiative heating is retarded and flattened due to the increasing mixing of air in the lower layers.

Summarizing, the katabatic regime dominates the circulation over the melting zone of the ice sheet. It exhibits a daily cycle, most pronounced at the ice edge, superposed on a background flow of typically 4 $\mathrm{m} \mathrm{s}^{-1}$. The daily cycle appears as the response to a forcing with two components:

- the local radiation balance and resulting daily cycle in cooling/heating of the air in the boundary layer;

- the horizontal pressure gradient associated with the gradient in heating rate across the tundra-ice transition, extending its influence only over a distance of 10 to $15 \mathrm{~km}$ onto the ice sheet.

From a theoretical point of view, the two different types of forcing arise when in the momentum equation the Boussinesq approximation is made and the horizontal axis is tilted to coincide with the surface (e.g., Mahrt 1982). One term is the buoyancy force, propor-
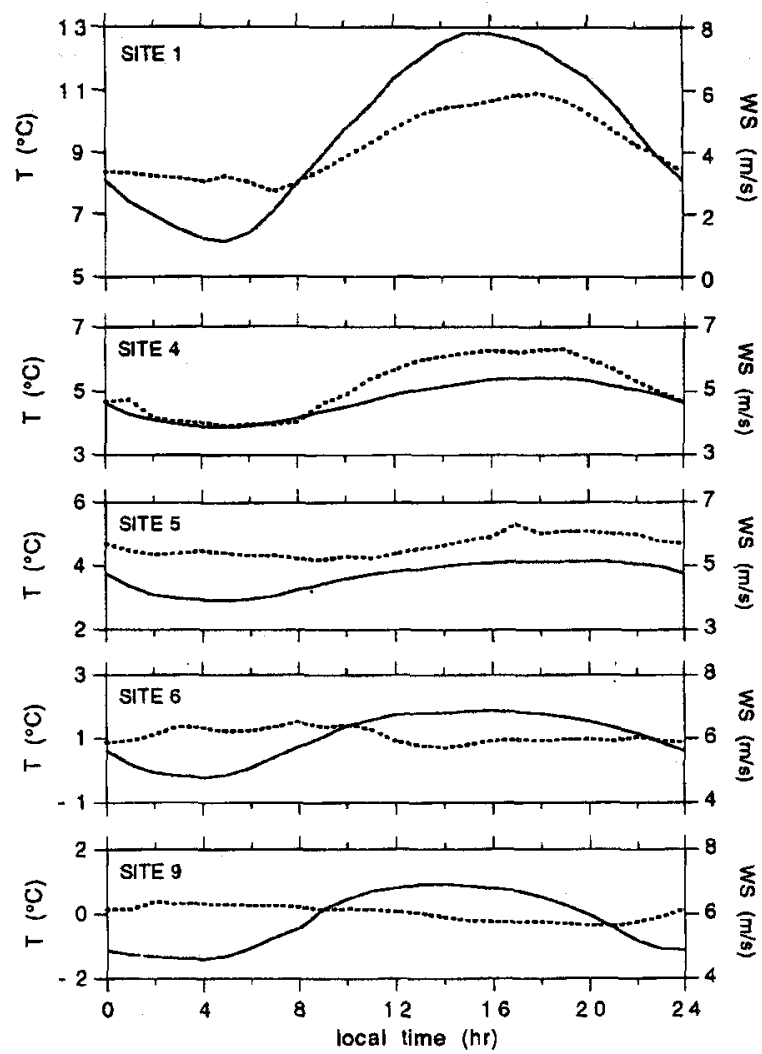

FiG. 8. Daily cycle of 6-m wind speed (dashed) and 2-m air temperature, averaged over all days.

tional to the surface slope and to the local perturbation of air temperature from a reference temperature profile; the other term is the horizontal pressure gradient. So even if the melting zone of the ice sheet would have zero slope, a sea-breeze-type circulation would be induced by the thermal contrast between tundra and ice sheet. An attempt to distinguish between the two forcing mechanisms will be made in a future analysis of the data in conjunction with a modeling study.

\section{Vertical structure of the katabatic flow at the ice edge}

An analysis of the balloon soundings sheds light on the structure of the katabatic layer when it extends from the ice sheet. A series of profiles, taken on 14 July, provides a characteristic picture. In Fig. 9, six soundings are shown, and the graphs present temperature, wind speed, and wind direction (humidity is not shown). Each sounding took about one hour: 30 min to go up, the remaining time to go down. Sampling of the various quantities was done every $10 \mathrm{~s}$. All data points have been used in preparing the graphs, to give 

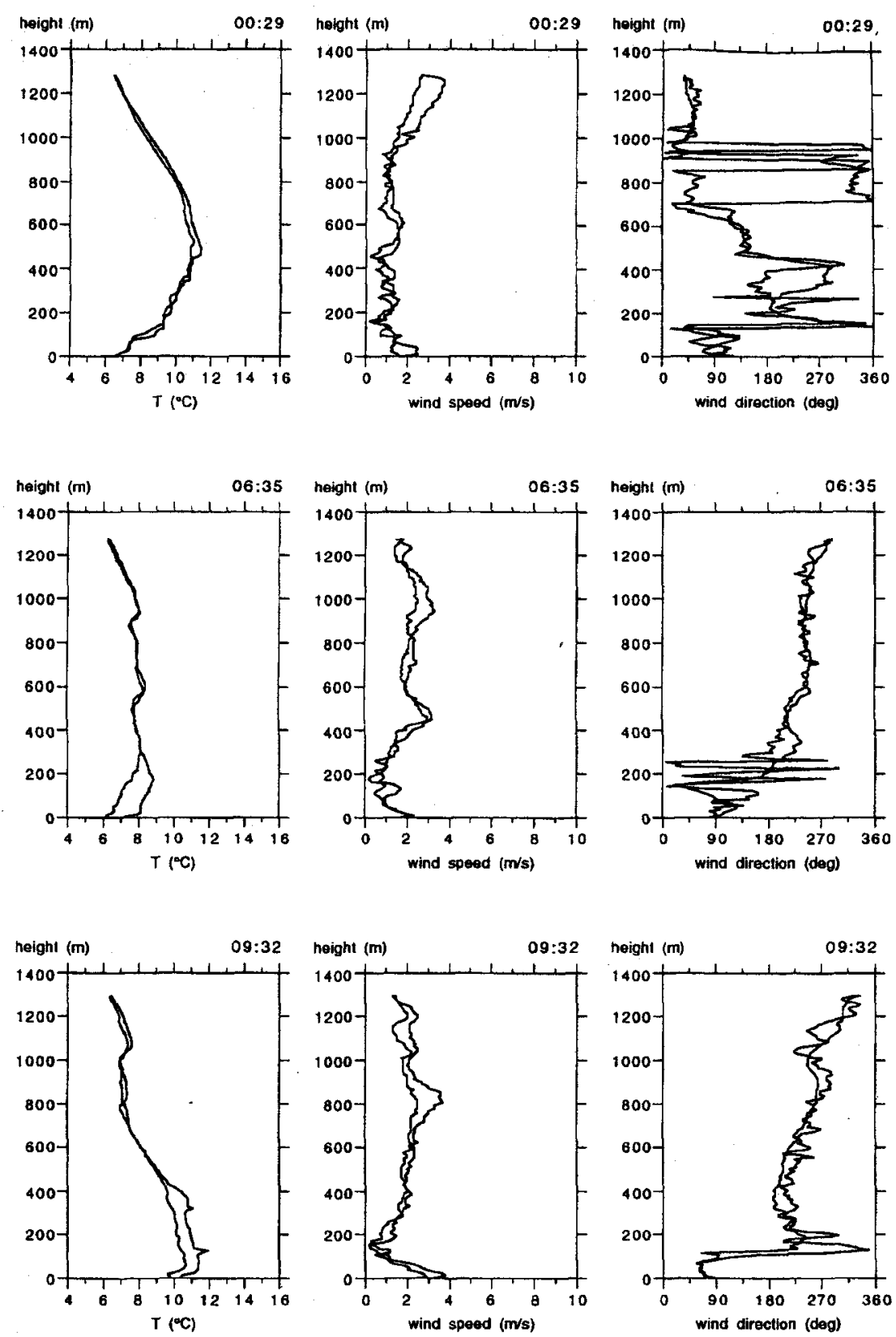

Fig. 9. Soundings obtained with the tethered balloon on 14 July 1991. Sampling was every 10 s. Both up- and downward branches are shown (see text)

an impression of variability as well as the difference between the up- and downgoing soundings. Obviously, when quantities change significantly within an hour, this will be reflected in the graphs. Note, for instance, that the downgoing branch for temperature at 0635 (all times are local) indicates a $2^{\circ} \mathrm{C}$ temperature rise in the lower $200 \mathrm{~m}$.
The graphs for 0029 show a structure typical for fair weather conditions: a stable stratification below the 500-m level and weak winds throughout the lowest kilometer of the troposphere. At 0635 the middle and upper part of the profile has cooled further, but heating at the surface has started. Winds are still weak. At 0932 a convective mixed layer has formed, and close to the surface the developing katabatic flow from the ice sheet shows up clearly. The highest wind speed is now found close to the surface, and the wind direction exhibits a marked change (from easterly to westerly) at a height of about 150 $\mathrm{m}$. At 1240 the variance along the profiles reaches a maximum (note the ragged appearance of the temperature curves, indicative of well-developed convectively driven turbulence). The surface inversion reaches a value of $3^{\circ}$ to $4^{\circ} \mathrm{C}$. The level at which the wind turns is now found between 250 and $300 \mathrm{~m}$. The profiles for 1835 and 2133 show how the mixed layer calms down. At 2133 the inversion starts to grow upward due to the negative radiation balance, and the situation becomes close to the 0029 picture again.

It is interesting to see that, in the 0932 and 1240 pictures, the level at which the wind turns from east to west is found much higher than the top of the cold layer (which is at a few tens of meters only). This suggests the existence of a relatively stable layer a few hundred meters deep, representing the large-scale katabatic regime. This example, as well as soundings from other days, shows that a return flow at higher levels, by which warm air is advected from the tundra onto the ice sheet, is an important feature. 


\section{Some aspects of the boundary-layer structure at site 9}

Figure 10 shows mean daily cycles of potential temperature (with respect to the surface) for six levels at site 9 . The averaging was done by superimposing the daily cycles from 27 June until 26 July. Differences in the daily temperature range appear to be rather small: at the 0.2-m level, it is about $2.7 \mathrm{~K}$, increasing to about $3.3 \mathrm{~K}$ at the $30-\mathrm{m}$ level. This points to significant vertical mixing, in spite of the stable stratification that is present most of the time. The small shift in the phase of the daily cycle when going upward is consistent with this.

The obtained RASS temperature data are not covering the entire period. Sampling was done at varying intervals, ranging from once per hour to four times per hour. In total, about 900 temperature profiles were obtained, 600 of which reached at least the 110 . $\mathrm{m}$ level. The data show that even at this height a weak daily temperature cycle is present, having an amplitude of a few tenths of a degree and opposite phase (with respect to the cycle at the surface).

The SODAR measurements give a good impression of the height of the boundary layer. If we define this height by a signal-to-noise ratio of the SODAR of $5 \mathrm{~dB}$, values between 90 and $150 \mathrm{~m}$ are found. Minimum values normally occur around 1600 local time, maximum values around 0600 . The boundary layer over the Greenland ice sheet is usually characterized by a stable stratification, maintained by a negative energy balance at the surface due to radiative cooling and a downward turbulent heat flux over melting areas in summer. At
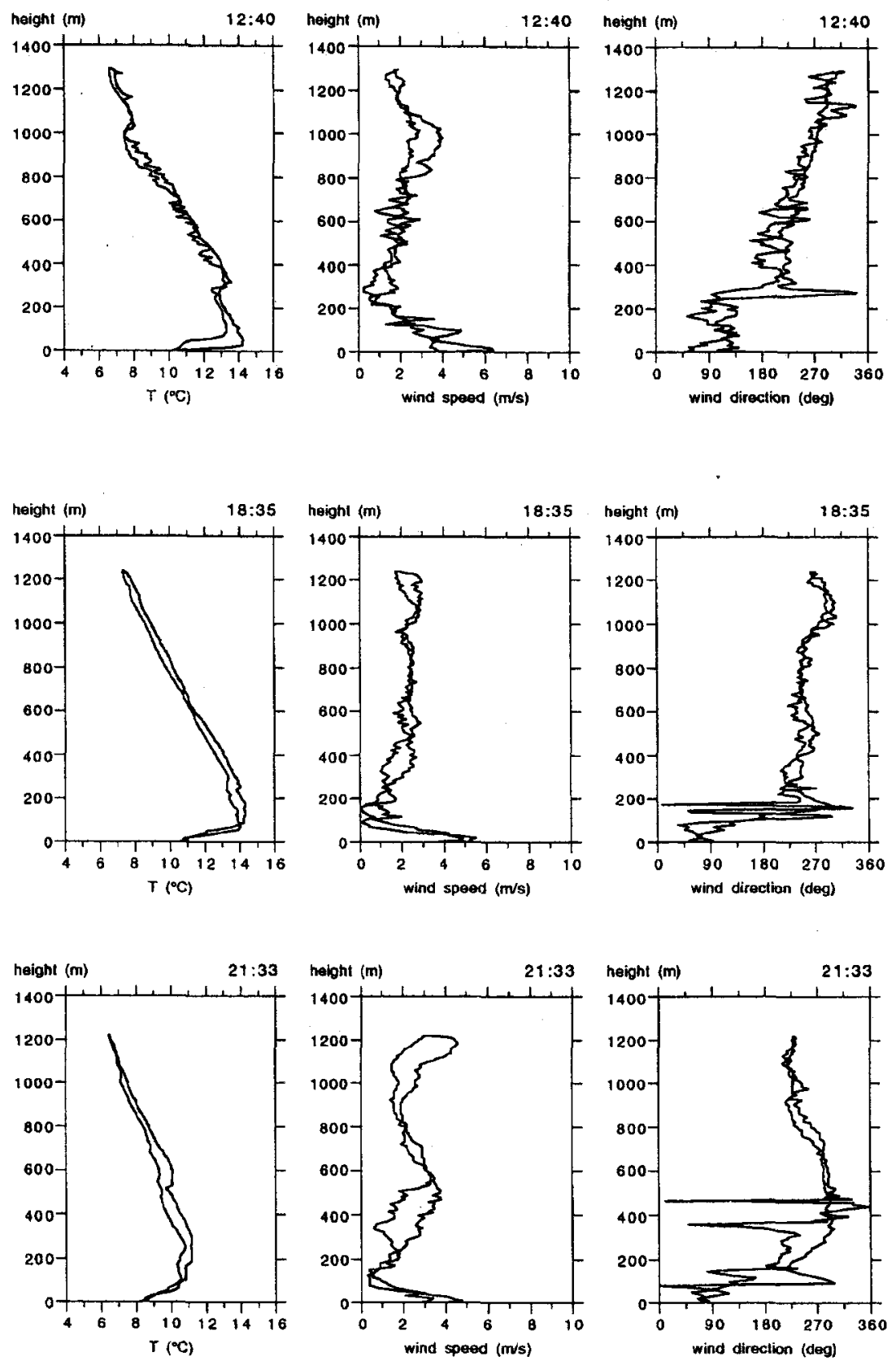

FIG. 9 continued. Soundings obtained with the tethered balloon on 14 July 1991 . Sampling was every $10 \mathrm{~s}$. Both up- and downward branches are shown (see text). 


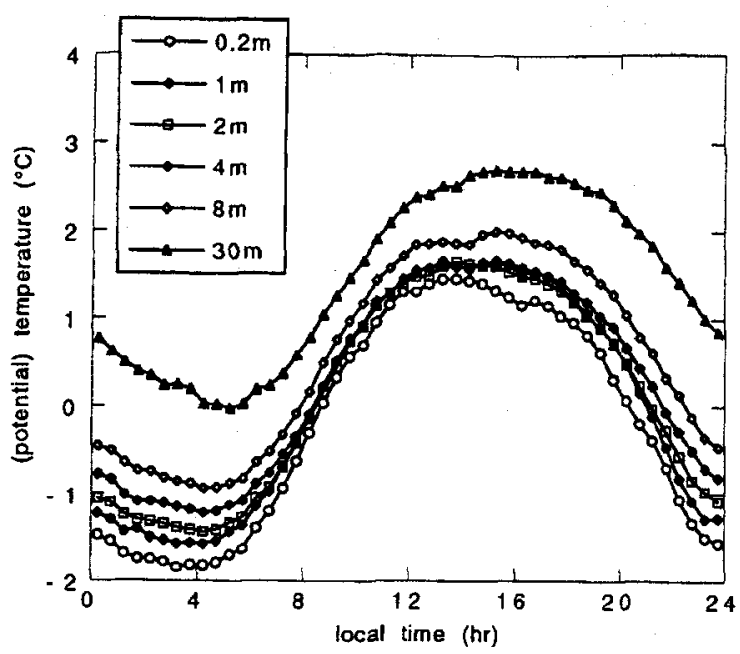

FIG. 10. Mean daily cycles of potential temperature (with reference to the surface elevation at the measuring site) at six levels, averaged over the period 27 June-26 July.

instruments. Close to the surface, the wind direction makes an angle of about $60^{\circ}$ with the fall line of the topography. When going up, the wind veers considerably, between $30^{\circ}$ and $50^{\circ}$ in the first $100 \mathrm{~m}$.

Understanding turbulent transport in the stable boundary layer is a key issue in modeling the surface energy budget of the ice sheet. As discussed earlier, the decrease of potential temperature in the katabatic flow toward the ice edge points to a substantial downward turbulent heat flux. Profile methods have hardly been verified for katabatic flows over vast melting regions, and we hope to make an interesting contribution on the basis of the dataset obtained at site 9 . Most of the eddy flux measurements still have to be analyzed. In Fig. 12 we show only a comparison of friction velocity obtained from the eddy flux measurements at
4 and $13 \mathrm{~m}$. The friction velocity appears to decrease with height, which is typical for a stable and thin boundary layer.

\section{Conclusions}

From a meteorological point of view, the melting zone of the Greenland ice sheet forms a unique region to study the structure of a stably stratified boundary layer with significant wind speeds, and consequently, relatively large turbulent transfers. One of the interesting aspects is the horizontal homogeneity of the boundary layer, which is never encountered over the melting zones of mountain glaciers where similar studies have been performed (e.g., Munro and Davies 1978).

The experiments have delivered a dataset from which we hope to gain more insight into the structure of katabatic flows, the parameterization of turbulent exchange in stable conditions, and the importance of energy exchange between tundra and ice sheet. In addition, we expect the dataset to be of value for validation of satellite-derived parameters of the icesheet surface such as albedo, roughness, and presence of liquid water.

Acknowledgments. Many people were involved in the planning and realization of the field experiments. We would like to thank N.J. Bink, R. Bintanja, L. Bos, M. van den Broeke, F. Cannemeijer, L. Conrads, P. Duynkerke, E.A.C. Henneken, P. Fortuin, A. Russell, R. van der Wal, and J. de Weger (scientists and students) for their participation in GIMEX-90 and GIMEX-91. We particularly acknowedge the dedication of the technicians: $H$. Bakker, W. Boot, M. Groen, Th. Hamer, J. de Lange, M. Portanger, and H. Snellen. Special thanks also go to the staff of the weather service in Søndre Strømfjord for their invaluable help.

Substantial financial support was obtained from the Dutch National Research Programme on Global Air Pollution and Climate
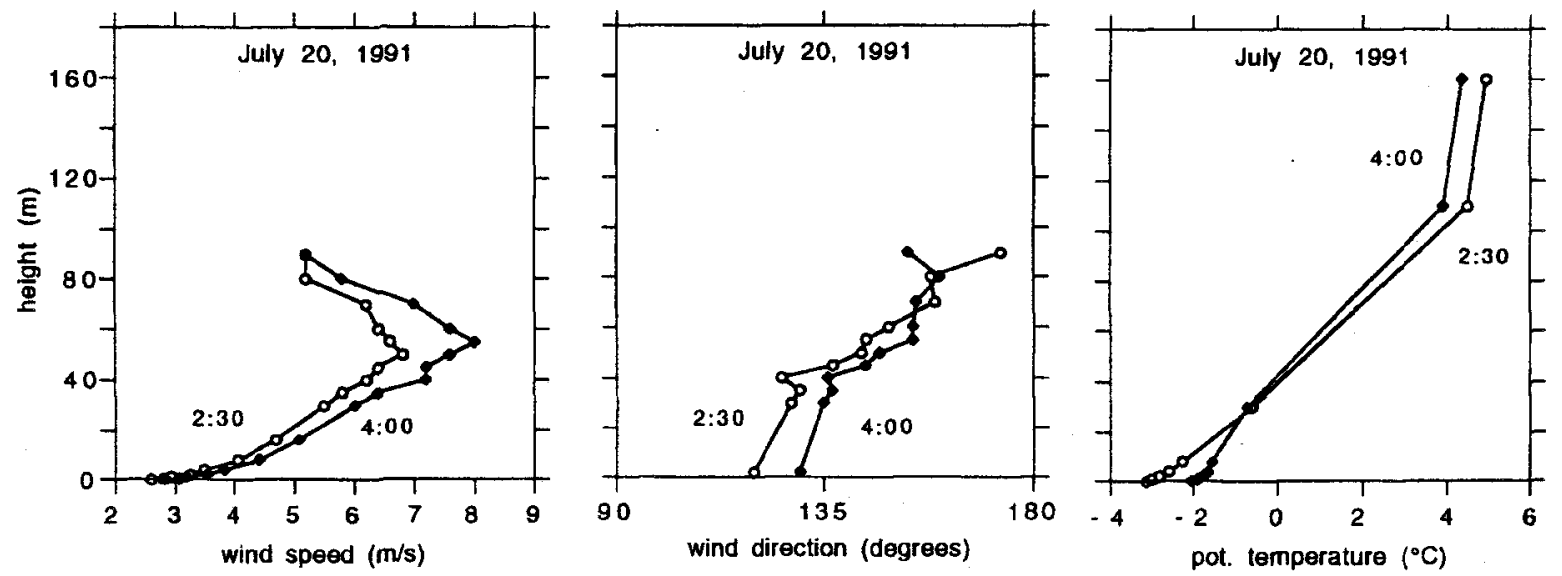

FIG. 11. A case of a well-developed katabatic flow. Shown are data for 20 July; 0230 and 0400 local time. 


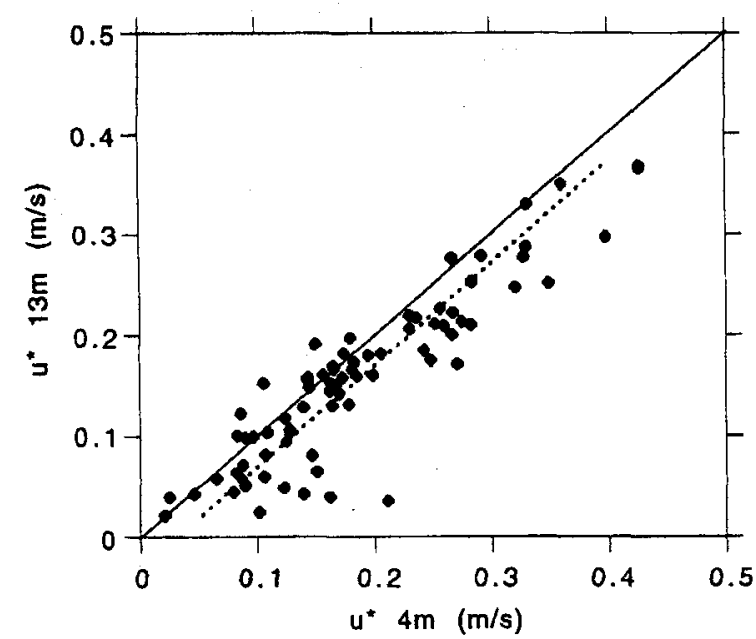

FiG. 12. Comparison of friction velocity $u^{*}$ according to the eddy flux measurements at 4 and $13 \mathrm{~m}$. Data points were taken at random from the entire dataset.

Change (Contract 276/91-NOP), from the Commission of the European Communities (Contract EPOC-CT90-0015), and from the Netherlands Organisation for Scientific Research (Werkgemeenschap $\mathrm{CO}_{2}$-Problematiek).

\section{References}

Ambach, W., 1963: Untersuchungen zum Energieumsatz in der Ablationszone des Grönlandischen Inlandeises. Medd. om Grenland, 174 (4), $311 \mathrm{pp}$.

- 1974: The influence of cloudiness on the net radiation balance of a snow surface with a high albedo. J. Glaciol., 13 (67), $73-84$.

_- 1979: Zur Wärmehaushalt des Grönlandischen Inlandeises: Vergleichende Studie im Akkumulationsgebiet- und Ablationsgebiet. Polarforschung, 49, 44-54.

Mahrt, L., 1982: Momentum balance of gravity flows. J. Atmos. Sci., 39, 2701-2711.

Munro, D.S., and J.A. Davies, 1978: On fitting the log-linear mode to wind speed and temperature profiles over a melting glacier. Bound.-Layer Meteor., 15, 423-437.

Oerlemans, J., 1991: The mass balance of the Greenland ice sheet Sensitivity to climate change as revealed by energy-balance modelling. Holocene, 1, 40-49.

Ohmura, A., 1987: New temperature distribution maps for Greenland. Z. Gletscherkd. Glaziaigeol., 23, 1-45.

Van der Wal, R.S.W., and A.J. Russell, 1993: Energy balance calculations and meltwater runoff near Søndre Strømfjord, West Greenland. Global and Planetary Change, submitted.

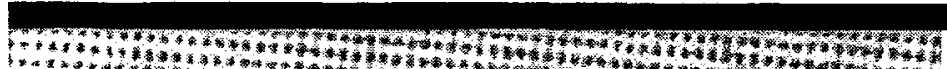

1.t.

PREPRANT $\vee O E$ UVE:

AMERICAN

METEOROLOGICAL

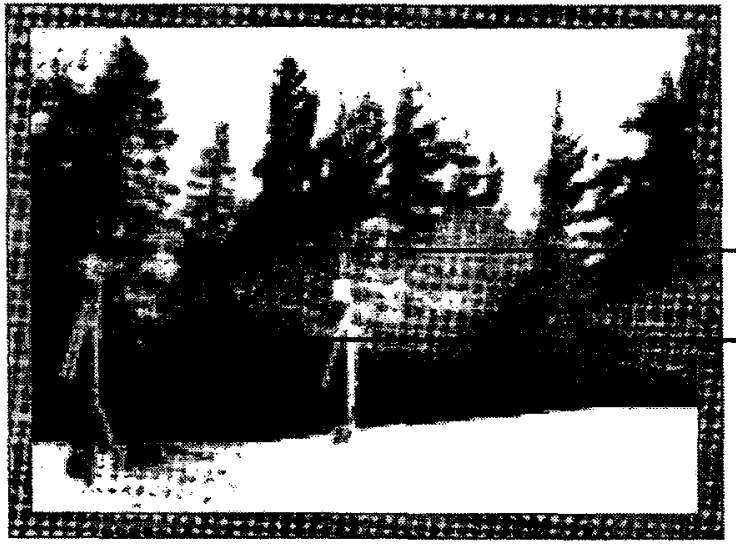

SOCIETY

RAIN ENHANCEMENT

HAIL SUPPRESSION

SNOWPACK AUGMENTATION

CLOUD SEEDING

CROP PRODUCTION

Symposium on Planned and Inadvertent

January 5-10, 1992

Weather Modification

Atlanta, Georgia

(01992 American Meteorological Society, softbound, 165pp, \$45/list,

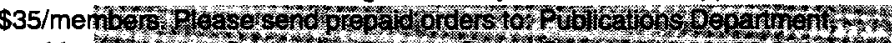

American Meleøologleal soo. 